\title{
Results of treatment of stage III glottic laryngeal cancer with chemoradiotherapy. Intensity modulated radiotherapy
}

\author{
Sara Olivia Ramos-Romero ${ }^{\text {* }}$, Rubén Figueroa-Aragón² and Rodrigo Silva-Martínez ${ }^{3}$ \\ ${ }^{1}$ Fourth-year Resident; ${ }^{2}$ Radio-oncolgy Course Assistant Professor; ${ }^{3}$ Surgical Oncology Specialist. Oncology Hospital, CMN Siglo XXI, IMSS, Ciudad \\ de México, Mexico
}

\begin{abstract}
Introduction: Laryngeal cancer is one of the most common head and neck neoplasms. Most cases are diagnosed at advanced stages. In clinical Stage III larynx cancer organ preservation protocols, chemoradiotherapy is the treatment of choice, with high local control and laryngectomy free survival rates in well selected patients. In our country, exploration of this results has not been made. Objectives: To retrospectively describe organ preservation, local control and morbidity after a two years follow-up. Materials and Methods: Clinical and electronic records of patients diagnosed with glottic laryngeal cancer Stage III T3NOMO treated with intensity-modulated radiation therapy (IMRT) concomitant with chemotherapy were reviewed in the period from January 2013 to December 2015. The study design was descriptive, observational, transversal and retrospective. Results: In the period between 2013 and 2015 at CMN SIGLO XXI Oncology Hospital, 266 patients with laryngeal cancer were treated; only 11 patients met the inclusion criteria for our study. After 2 years, locoregional control and organ preservation were $100 \%$, no 3 or 4 grade morbidity was observed. Conclusion: In our study, the IMRT concomitant with chemotheraphy in glottic laryngeal cancer Stage III T3NOMO offers $100 \%$ organ preservation, and locoregional control, with acceptable morbidity at 2 years.
\end{abstract}

Key words: Glottic laringeal cancer. Organ preservation. Locoregional control. Morbidity. IMRT technique.

Available online: 30-05-2019 Gac Mex Oncol. 2018;17:48-54 www.gamo-smeo.com 


\section{Introduction}

Malignant neoplasms of the larynx account for less than $2 \%$; however, it is one of the most common head and neck neoplasms ${ }^{1}$. In the world, there are 130,000 new cases of laryngeal cancer and 70,000 deaths every year. In Mexico, the incidence in 2012 was 2,479, with a mortality of 891 and 5-year prevalence of 6,990, being one of the most common neoplasms in both genders $^{2}$. In Mexico, at least $65 \%$ of cases are diagnosed at advanced stages ${ }^{3}$.

Malignant neoplasms of the larynx are caused by tobacco and alcohol consumption in more than $90 \%$ of cases. The most common tumor histopathology is squamous cell carcinoma, which accounts for $>95 \%$. Its incidence and distribution according to subsite is: the glottis $69 \%$, supraglottis $30 \%$ and subglottis $1 \%$; when early diagnosed, $60 \%$ are located in the glottis., 4,6

Nodal incidence for glottic cancer according to tumor size is as follows: T1 0-2\%, T2 2-7\% and T3-T4 15-30\% ${ }^{11}$. Tumors of the glottic larynx usually occur with dysphonia and are more often diagnosed at early stages. Other symptoms include odynophagia, sore throat, otalgia (through the Arnold nerve/CN X), aspiration and cervical tumor ${ }^{7,8}$.

The basis of diagnosis is physical examination, with the key exploration being laryngofibroscopy ${ }^{9}$. There is no screening method for these pathologies ${ }^{10-13}$. Computed tomography (CT) and magnetic resonance are imaging tests for locoregional staging. Positron emission tomography-CT plays two roles in this pathology: detection of distant metastases in locally advanced stages and aid the delimitation of target volumes ${ }^{14,15}$.

The most important adverse prognostic factors are increases in $\mathrm{T}$ and $\mathrm{N}$ stages; others include gender, age, performance status and a variety of tumor pathological features, such as the grade and depth of invasion ${ }^{16-18}$.

Historically, treatment in advanced but resectable tumors has been laryngectomy or total pharyngolaryngectomy plus adjuvant treatment, with non-functional results, moderate morbidity results and good locoregional control. Currently, with concomitant chemotherapy/ radiotherapy (CT/RT) techniques, functionality, low morbidity and good locoregional control are achieved, with higher organ preservation rates. The drug of choice for radical CT/RT is cisplatin (CDDP), and as an alternative to this drug, cetuximab or the combination of carboplatin/5-fluorouracil (5-FU) can be administered. For induction, the combination of choice is the docetaxel/CDDP/5-FU-based triplet ${ }^{19,20}$.
In organ-preservation protocols for stage III laryngeal cancer, with CT/RT larynx-preservation intent, rates of LC of $66 \%$ and LFS of $60 \%$ have been achieved, with surgery being reserved for cases where tumor reduction to less than $50 \%$ is not obtained with induction CT cycles, with survival rates similar to those for surgery plus adjuvant RT, with the drawback of CT/RT toxicity ${ }^{21,22}$.

In a study of the Department of Veterans Affairs, induction CT (CDDP-FU, 3 cycles) and RT (6,600-7,600 cGy) were observed to be effective for larynx preservation in up to $64 \%$ of cases, thus improving the quality of life of these patients. There were no differences in overall survival between both induction CT and concomitant CT/RT arms, with lower rates of distant metastasis $(p=0.016)$. Overall and disease-free survival of these patients was $64 \%$, with a median follow-up of 33 months ${ }^{23}$.

Larynx preservation does not mean total function preservation. Prior to proposing CT/RT, it is necessary to check for adequate function of at least one cricoarytenoid unit and an acceptable functional breathing reserve ${ }^{24-26}$.

In the study by Forastiere et al., results were obtained in the concomitant QT/RT group, with $88 \%$ organ preservation, with an emphasis on speech and swallowing, as well as LC of $78 \%$, in comparison with $61 \%$ with induction CT, with no impact on overall survival in either arm. However, there was a lower incidence of distant metastasis and longer disease-free survival (DFS) with the regimens that included QT, with $84 \%$ organ preservation being confirmed after three years of follow-up in the concomitant CT group ${ }^{26,27}$.

In a meta-analysis of 84 randomized clinical trials by Pignon et al., 602 patients with cancer of the larynx and hypopharynx treated with PF-based induction CT with organ preservation intent were analyzed, with $23 \%$ organ preservation at five years being demonstrated ${ }^{28}$.

It is important mentioning that, in the cases of bulky tumors, several trials have demonstrated that induction CT followed by RT yields the same results in terms of overall survival, DFS and laryngeal preservation (up to $59 \%$ ) in comparison with $\mathrm{CT} / \mathrm{RT}^{28-30}$.

In tumors of the head and neck, intensity modulated radiation therapy (IMRT) has two potential advantages: covering the tumor with irradiation and decreasing toxicity to neighboring organs, due to the great complexity of the different structures that make up this area, as well as to their small size and extreme closeness between each other. IMRT does not increase toxicity and thus protects critical organs and improves patient quality of life ${ }^{30}$. 
Most common long-term complications include xerostomia, lymphedema, dysgeusia, cranial nerve $\mathrm{X}$ lesions, vascular events and fibrosis ${ }^{31}$.

Cozzi et al., in a head and neck cancer protocol based on IMRT treatment with multileaf collimator vs. 3D conformal radiation, evaluated dose plans in terms of physical quantities based on dose-volume histograms and isodose distributions. The authors found that irradiation of parotid glands or spinal cord improved; for parotids, it was reduced from 59 to 41 Gy $(p<0.001)$, while for the spinal cord, it was reduced from about 40 to about 30 Gy; thus, they concluded that the technique with IMRT reduces at-risk organs morbidity 32 .

We should mention that the most common long-term complication of RT and CT/RT for head and neck cancer is xerostomia, and the severity of this condition is dose-dependent, with parotid dysfunction being detectable at a dose of 10 to $15 \mathrm{~Gy}$, and administration of a mean dose of 40 to 50 Gy negatively affecting the quality of life. Other complications include lymphedema (airway compromise and dysphagia), decreased taste and smell, nerve injuries, vascular events and fibrosis, all of them largely being decreased thanks to techniques such as IMRT ${ }^{33,34}$.

Miah et al. assessed stage III and IV laryngeal cancer treated with concomitant CT/RT plus conventional fractionation vs. escalating-dose IMRT, with good results in locoregional control and progression-free survival in both groups (64.2 vs. $78.4 \%$ ) and preservation rates of $88.7 \%$ vs. $96.4 \%$, all in favor of escalating doses with IMRT. It should be noted that grade 3 toxicity was observed for dysphagia and benign stenosis of the phary$\mathrm{nx}$ at one year, which was higher in the escalating-dose group; other toxicities were comparable in both groups ${ }^{35}$.

The results confirm the efficacy of IMRT in head and neck cancer. This technique offers excellent results in locoregional control, overall survival and at-risk organs decreased morbidity, thus improving the results in cancer of the laryn $x^{36}$.

The purpose of the present study was to retrospectively describe organ preservation, locoregional control and two-year morbidity.

\section{Material and methods}

We reviewed the clinical and electronic records of patients diagnosed with stage III T3NOMO glottic laryngeal cancer treated with induction CT and IMRT concomitant with CT at National Medical Center Siglo XXI in the period comprised between January 2013 and December 2015.
Table 1. Patient characteristics

\begin{tabular}{|l|c|}
\hline Characteristics & Range/Average \\
\hline Age (mean) & 62 years (47-75) \\
\hline Gender (M:F) & M:11 F:0 (M:100\%) \\
\hline Hemoglobin g/dL (mean) & $14.24(9.84-18.3)$ \\
\hline Comorbidities & $5(45 \%)$ \\
\hline DM & $1(9 \%)$ \\
\hline HBP & $3(27.2 \%)$ \\
\hline Other & $1(9 \%)$ \\
\hline Smoking & $11(100 \%)$ \\
\hline Alcohol consumption & $11(100 \%)$ \\
\hline M: male; F: female; DM: diabetes mellitus; HBP: high blood pressure.
\end{tabular}

The design of the study was descriptive, observational, cross-sectional and retrospective. We included patients with stage III T3NOMO glottic laryngeal cancer, treated with IMRT concomitant with CT in the period comprised between 2013 and 2015, older than 18 years, of both genders and histological type of squamous cell carcinoma. Patients previously treated with RT, treated with another RT technique, patients with previous surgery and patients with second neoplasms were excluded.

This study does not require sample size calculation, since it is merely a descriptive study. Our inclusion variable was IMRT and the observed variables were locoregional control, morbidity and organ preservation, while the descriptor variables were age, gender, comorbidities, smoking, alcohol consumption and hemoglobin concentration. The dosimetric descriptor variables were the conformity index $(\mathrm{Cl})$, homogeneity index $(\mathrm{IH})$, prescription dose to the planning target volume (PTV), maximum dose to gross tumor volume (GTV) and maximum dose to at-risk organs.

Our protocol follows the ethical guidelines of the declaration of Helsinki of the World Medical Association, and was submitted to and accepted by the local research committee of the hospital where the study was carried out.

\section{Statistical analysis}

After clearance of the database, a descriptive analysis was carried out, which yielded frequencies and percentages for qualitative variables, and central tendency and dispersion measures for quantitative variables. The Microsoft Excel ${ }^{\circledR}$ and SPSS ${ }^{\circledR}$ v22 programs were used. 
Table 2. Dosimetric descriptor variables

\begin{tabular}{|l|c|c|c|c|c|}
\hline Patient no. & Prescription dose to PTV & Maximum dose to GTV & Mean dose to GTV & CI & HI \\
\hline 1 & $66 \mathrm{~Gy} / 33 \mathrm{Fx}$ & $8074.9 \mathrm{cGy}$ & $7686.8 \mathrm{cGy}$ & 1.24 & 0.16 \\
\hline 2 & $65 \mathrm{~Gy} / 35 \mathrm{Fx}$ & $7299.3 \mathrm{cGy}$ & $6902.2 \mathrm{cGy}$ & 1.02 & 0.219 \\
\hline 3 & $72.08 \mathrm{~Gy} / 34 \mathrm{Fx}$ & $7697 \mathrm{cGy}$ & $7384.3 \mathrm{cGy}$ & 1.17 & 0.07 \\
\hline 4 & $69.96 \mathrm{~Gy} / 33 \mathrm{Fx}$ & $7471.6 \mathrm{cGy}$ & $7238.3 \mathrm{cGy}$ & 1.23 & 0.04 \\
\hline 5 & $69.96 \mathrm{~Gy} / 33 \mathrm{Fx}$ & $7961 \mathrm{cGy}$ & 1.16 & 0.08 \\
\hline 6 & $69.96 \mathrm{~Gy} / 33 \mathrm{Fx}$ & $7597.4 \mathrm{cGy}$ & $7292.5 \mathrm{cGy}$ & 1.37 & 0.21 \\
\hline 7 & $50 \mathrm{~Gy} / 25 \mathrm{Fx}$ & $5538.1 \mathrm{cGy}$ & $7280.2 \mathrm{cGy}$ & 2.18 & 0.07 \\
\hline 8 & $68.4 \mathrm{~Gy} / 38 \mathrm{Fx}$ & $7586 \mathrm{cGy}$ & $7252.4 \mathrm{cGy}$ & 1.07 & 1.07 \\
\hline 9 & $68.4 \mathrm{~Gy} / 38 \mathrm{Fx}$ & $7850.4 \mathrm{cGy}$ & $7340.8 \mathrm{cGy}$ & 1.19 \\
\hline 10 & $69.96 \mathrm{~Gy} / 33 \mathrm{Fx}$ & $7860.7 \mathrm{cGy}$ & $7453.7 \mathrm{cGy}$ & 1.59 \\
\hline 11 & $68.4 \mathrm{~Gy} / 38 \mathrm{Fx}$ & $7777.5 \mathrm{cGy}$ & $7380.8 \mathrm{cGy}$ & 1.63 \\
\hline Average & $67.10 \mathrm{~Gy} / 33.9 \mathrm{Fx}$ & $7519.4 \mathrm{cGy}$ & $7135.02 \mathrm{cGy}$ & 1.35 \\
\hline
\end{tabular}

$\mathrm{Cl}$ : conformity index; HI: homogeneity index; PTV: planning target volume.

Table 3. Acute morbidity

\begin{tabular}{|l|c|c|c|c|c|}
\hline & Grade 1 & Grade 2 & Grade 3 & Grade 4 & Grade 5 \\
\hline Mucositis & $3(27.2 \%)$ & $8(72.7 \%)$ & $0(0 \%)$ & $0(0 \%)$ & $0(0 \%)$ \\
\hline Radiodermatitis & $6(54.54 \%)$ & $5(45.4 \%)$ & $0(0 \%)$ & $0(0 \%)$ & $0(0 \%)$ \\
\hline Dysphagia & $3(27.2 \%)$ & $0(0 \%)$ & $0(0 \%)$ & $0(0 \%)$ & $0(0 \%)$ \\
\hline Xerostomia & $0(0 \%)$ & $0(0 \%)$ & $0(0 \%)$ & $0(0 \%)$ & $0(0 \%)$
\end{tabular}

\section{Results}

At the CMN SIGLO XXI Oncology Hospital, 266 patients with laryngeal cancer received treatment in the period comprised between 2013 and 2015, but only 11 of them met the inclusion criteria of our study, since the rest of patients with stage III T3NOMO were initially treated with radical surgery.

Patient average age was 62 years, with a range of 47 to 75 years; $100 \%$ were men, all with a positive history of more than 20 years of alcohol consumption and smoking. As for comorbidities, $27.2 \%$ were hypertensive and $9 \%$ had type 2 diabetes mellitus, 9\% with COPD. Mean hemoglobin level was $14.24 \mathrm{~g} / \mathrm{dL}$, with a range of 9.84 to $18.3 \mathrm{~g} / \mathrm{dL}$; median value was $14 \mathrm{~g} / \mathrm{dL}$ (Table 1 ).

IMRT was our inclusion constant, with $100 \%$ of our group being treated with this technique modality, $81.8 \%$ of them with VMAT type and $18.1 \%$ with Step and Shoot. Our dosimetric descriptor variables were the prescription dose to PTV, maximum and average dose to GTV, $\mathrm{Cl}, \mathrm{IH}$ and maximum and mean dose received by at-risk organs, according to dose-volume histograms and isodose distributions (Table 2).

Mean dose was $67.10 \mathrm{~Gy}$, ranging between 50 and $72.08 \mathrm{~Gy}$, with $\mathrm{Cl}$ being observed to be 1.35 on average, which indicates an ideal conformity according to the Radiation Therapy Oncology Group (RTOG), while HI was 0.261 on average, which was deemed to comply with the RTOG protocol.

The most widely used induction chemotherapeutic agent was the triplet based on TPF (docetaxel/CDDP/5-FU) in $63.6 \%$ of cases, FUP (CDDP-FU) in $36.3 \%$, two cycles and continued with concomitant CT/RT with CDDP.

The most common acute morbidity was grade II mucositis in $72.7 \%$, followed by grade I radiodermatitis in $54.54 \%$ and grade I mucositis and dysphagia in $27.2 \%$. There were no morbidities higher than grade II (Table 3). 
Table 4. Late morbidity

\begin{tabular}{|l|c|c|c|c|c|}
\hline & Grade $\mathbf{1}$ & Grade $\mathbf{2}$ & Grade $\mathbf{3}$ & Grade 4 & Grade $\mathbf{5}$ \\
\hline Mucositis & $0(0 \%)$ & $0(0 \%)$ & $0(0 \%)$ & $0(0 \%)$ & $0(0 \%)$ \\
\hline Radiodermatitis & $6(54.5 \%)$ & $0(0 \%)$ & $0(0 \%)$ & $0(0 \%)$ & $0(0 \%)$ \\
\hline Dysphagia & $2(18.1 \%)$ & $0(0 \%)$ & $0(0 \%)$ & $0(0 \%)$ & $0(0 \%)$ \\
\hline Xerostomia & $11(100 \%)$ & $0(0 \%)$ & $0(0 \%)$ & $0(0 \%)$ & $0(0 \%)$ \\
\hline
\end{tabular}

Table 5. Descriptor variables

\begin{tabular}{|c|c|c|c|c|c|c|c|c|c|}
\hline & CI & HI & $\begin{array}{l}\text { Prescription } \\
\text { dose to PTV }\end{array}$ & $\begin{array}{l}\text { Maximum } \\
\text { dose to GTV }\end{array}$ & $\begin{array}{l}\text { Mucositis } \\
\text { grade }\end{array}$ & $\begin{array}{l}\text { Radiodermatitis } \\
\text { grade }\end{array}$ & $\begin{array}{l}\text { Dysphagia } \\
\text { grade }\end{array}$ & $\begin{array}{l}\text { Locoregional } \\
\text { control at } \\
2 \text { years }\end{array}$ & $\begin{array}{l}\text { Organ } \\
\text { preservation } \\
\text { at } 2 \text { years }\end{array}$ \\
\hline 1 & 1.24 & 0.16 & $66 \mathrm{~Gy} / 33 \mathrm{Fx}$ & 8074.9 cGy & 1 & 2 & 1 & Yes & Yes \\
\hline 2 & 1.02 & 0.219 & $65 \mathrm{~Gy} / 35 \mathrm{Fx}$ & $7299.3 \mathrm{cGy}$ & 2 & 1 & 2 & Yes & Yes \\
\hline 3 & 1.17 & 0.07 & $72.08 \mathrm{~Gy} / 34 \mathrm{Fx}$ & 7697 cGy & 1 & 1 & 0 & Yes & Yes \\
\hline 4 & 1.23 & 0.04 & $69.96 \mathrm{~Gy} / 33 \mathrm{Fx}$ & $7471.6 \mathrm{cGy}$ & 1 & 2 & 0 & Yes & Yes \\
\hline 5 & 1.16 & 0.08 & $69.96 \mathrm{~Gy} / 33 \mathrm{Fx}$ & 7961 cGy & 2 & 2 & 0 & Yes & Yes \\
\hline 6 & 1.37 & 0.21 & $69.96 \mathrm{~Gy} / 33 \mathrm{Fx}$ & $7597.4 \mathrm{cGy}$ & 2 & 1 & 0 & Yes & Yes \\
\hline 7 & 2.18 & 0.07 & $50 \mathrm{~Gy} / 25 \mathrm{Fx}$ & $5538.1 \mathrm{cGy}$ & 2 & 1 & 0 & Yes & Yes \\
\hline 8 & 1.07 & 1.07 & $68.4 \mathrm{~Gy} / 38 \mathrm{Fx}$ & 7586 cGy & 2 & 1 & 0 & Yes & Yes \\
\hline 9 & 1.19 & 0.57 & $68.4 \mathrm{~Gy} / 38 \mathrm{Fx}$ & $7850.4 \mathrm{cGy}$ & 2 & 2 & 0 & Yes & Yes \\
\hline 10 & 1.59 & 0.09 & $69.96 \mathrm{~Gy} / 33 \mathrm{Fx}$ & $7860.7 \mathrm{cGy}$ & 1 & 1 & 0 & Yes & Yes \\
\hline 11 & 1.63 & 0.13 & $68.4 \mathrm{~Gy} / 38 \mathrm{Fx}$ & $7777.5 \mathrm{cGy}$ & 2 & 2 & 0 & Yes & Yes \\
\hline
\end{tabular}

$\mathrm{Cl}$ : conformity index; HI: homogeneity index; PTV: planning tumor volume; GTV: gross tumor volume.

The most common late morbidity was xerostomia in $100 \%$, followed by grade I radiodermatitis in $54.5 \%$ and grade II dysphagia in $18.1 \%$ of our study patients (Table 4).

In the study, the descriptor variables (Table 5) did not influence on organ preservation or morbidity. At 2 years, $100 \%$ locoregional control and organ preservation were achieved (Table 6).

\section{Discussion}

Glottic laryngeal cancer is caused in more than $90 \%$ of cases by tobacco and alcohol consumption, which generate a synergy, as reported in the study by Hashibe et al. (2007), similar to our study group, where $100 \%$ of patients had a positive history of more than 20 years of smoking and alcohol consumption. The combination of IMRT with concomitant CT in stage III T3NOMO glottic laryngeal cancer has obtained good results in terms of locoregional control, preservation rates and morbidity. In our study, organ preservation and locoregional control rates of $100 \%$ were obtained, similar to those reported in the literature with two-year follow-up, as described in the studies by Miah et al. (2012) and Forastiere et al. (2003). It is important noting that one of our patients underwent a tracheostomy at one and a half years of follow-up owing to pneumonia; however, in the last follow-up panendoscopy, no evidence of tumor activity was observed, and thus it is still considered a case of organ preservation, hence the importance for organ preservation criteria to be reestablished in our hospital.

Average administered dose was $67.10 \mathrm{~Gy} / 33.9 \mathrm{Fx}$ (fractions), with treatment volume adequate coverage with IMRT being obtained, thus favoring adequate homogeneity and conformity, as established by RTOG.

Different factors were assessed (gender, age and comorbidities), but in our study none was found to have significant impact, probably owing to the small sample size. 
Table 6. Organ preservation and locoregional control at two years

\begin{tabular}{|l|l|l|l|l|}
\hline Patient no. & Prescription dose to PTV & Organ preservation & Locoregional control & 0.9 \\
\hline 1 & $66 \mathrm{~Gy} / 33 \mathrm{Fx}$ & Yes & Yes & 0.9 \\
\hline 2 & $65 \mathrm{~Gy} / 35 \mathrm{Fx}$ & Yes & Yes & 0.9 \\
\hline 3 & $72.08 \mathrm{~Gy} / 34 \mathrm{Fx}$ & Yes & Yes & 0.8 \\
\hline 4 & $69.96 \mathrm{~Gy} / 33 \mathrm{Fx}$ & Yes & Yes & 0.8 \\
\hline 5 & $69.96 \mathrm{~Gy} / 33 \mathrm{Fx}$ & Yes & Yes & 0.8 \\
\hline 6 & $69.96 \mathrm{~Gy} / 33 \mathrm{Fx}$ & Yes & Yes & 0.9 \\
\hline 7 & $50 \mathrm{~Gy} / 25 \mathrm{Fx}$ & Yes & Yes & 0.8 \\
\hline 8 & $68.4 \mathrm{~Gy} / 38 \mathrm{Fx}$ & Yes & Yes & 0.8 \\
\hline 9 & $68.4 \mathrm{~Gy} / 38 \mathrm{Fx}$ & Yes & Yes & 0.8 \\
\hline 10 & $69.96 \mathrm{~Gy} / 33 \mathrm{Fx}$ & Yes & Yes & 0.8 \\
\hline 11 & $68.4 \mathrm{~Gy} / 38 \mathrm{Fx}$ & Yes & Yes & \\
\hline
\end{tabular}

PTV: planning tumor volume.

Table 7. Mean dose averages to healthy tissues in cGy

\begin{tabular}{|l|c|}
\hline At-risk organs & Mean dose \\
\hline Parotid glands & $2911.05 \mathrm{cGy}$ \\
\hline Esophagus & $2770.1 \mathrm{cGy}$ \\
\hline Posterior laryngeal wall & $5502.75 \mathrm{cGy}$ \\
\hline Jawbone & $2991.95 \mathrm{cGy}$ \\
\hline Spinal cord & $2400 \mathrm{cGy}$ \\
\hline
\end{tabular}

In our study, a hemoglobin concentration $>13 \mathrm{~g} / \mathrm{dL}$ prior to radiation was not a factor that influenced on the results, since it was not statistically significant. All patients had $100 \%$ locoregional control and organ preservation, unlike the results obtained in the study by Fein da et al. (1995).

Regarding morbidity, as assessed with the CTC version 3.0 and RTOG scales, grade II mucositis was found to be the most common, followed by grade I radiodermatitis, unlike figures reported in the literature, where higher morbidity rates are referred. As for late morbidity, xerostomia was present in $100 \%$ of our study group, similar to observations reported in the literature by Rancati et al. (2010).

As additional data, table 7 shows average doses to at-risk organs.

In the dose-volume histograms and isodose distributions, we obtained results of lower irradiation to the parotid glands and to other at-risk organs, with better results being obtained with the VMAT-type modality than those reported by Miah et al. (2012), Bride et al. (2007) and Bonner et al. (2005), with a consequent impact on overall morbidity.

However, the present study has some limitations, such as being a retrospective, cross-sectional study that had no follow-up, with a single evaluation at two years and with a low number of patients.

The present study may give rise to future protocols with prospective assessment, strict follow-up, randomized distribution and in accordance to clinical practice guidelines, or even to carrying out comparative studies between different treatment modalities.

\section{Conclusion}

In our study, IMRT in concomitance with CT in stage III, T3NOMO glottic laryngeal cancer offers $100 \%$ organ preservation and $100 \%$ locoregional control, with acceptable morbidity at two years.

\section{Conflict of interests}

The authors declare not having any conflict of interests.

\section{References}

1. Siegel RL, Miller KD, Jemal et al. Cancer statistics; 2016. Ca cáncer j clin 2016; 66: 7 . 
2. Globocan 2012: Estimated Cáncer Incidence, Mortality and Prevalence Wordwide in 2012.

3. Granados García, Arrieta Rodríguez, et al. Tratamiento del cáncer, oncología médica, quirúrgica y radioterapia. 2016 Editorial manual moderno SA de C.V. pág 272

4. Hashibe M, Boffetta P, Zaridze D, Shangina O, Szeszenia-dabrowska N Mates D, et al. Contribution of Tobacco And Alcohol To The High Rates Of Squamous Cell Carcinoma Of The Supraglottis And Glottis In Central Europe. am j epidemiol. 2007;165(7):814-20.

5. Menvielle G, luce D, Goldberg P, Bugel I, Leclerc A. Smoking, Alcohol Drinking And Cancer Risk For Various Sites Of The Larynx and Hypopharynx. a Case-Control Study In France. eur j cancer prev. 2004;13(3):165-72.

6. Pantel M, Guntinas-Lichius O: Laryngeal carcinoma: epidemiology, risk factors and survival. HNO 2012; 60 (1):32-40.

7. Chen AY, Halpern M. Factors Predictive Of Survival in Advanced Laryngeal Cancer. Bow Otolaryngol Head Neck Surg 2007; 133: 1270.

8. Hartl DM, Ferlito A, Brasnu DF, Langendijk JA, Rinaldo A, Silver CE, et al. Evidence-Based Review Of Treatment Options For Patients With Glottic Cancer. Head Neck. Marioni G, Marchese-Ragona R, Cartei G, Marchese F, Staffieri A. Current Opinion in Diagnosis and Treatment of Laryngeal Carcinoma. Cancer treat rev. 2006;32(7):504-15.

9. Nccn Clinical Practice Guidelines. disponible en: http://www.nccn.org.

10. Sharma DK, Sohal BS, Bal MS, Aggarwal S: Clinico-pathological study of 50 cases of tumour of larynx. Indian J Otolaryngol Head Neck Surg 2013:65 (Suppl 1):29-35.

11. O'neill Cb, O'neill Jp, Atoria Cl, et al. Complications Of Treatment And Survival In Advanced Laryngeal Cancer: A Population-Based Analysis. Laryngoscope 2014; 124: 2707.

12. Yilmaz T, Hoșal S, Gedikoglu G, et al.: Prognostic Significance of depth of invasion in cancer of the larynx. laryngoscope 108 (5): 764-8, 1998.

13. Fein da, lee wr, hanlon al, et al.: Pretreatment Hemoglobin Level Influences Local Control and Survival of t1-t2 Squamous Cell Carcinomas Of The Glottic Larynx. j clin oncol 1995.

14. Lango mn. Multimodal Treatment For Head and Neck Cancer. Surg Clin north AM 2009; 89:43.

15. Silver ce, Beitler Jj, Shaha Ar, et al. Current Trends In The Initial Treatment Of Laryngeal Cancer: The Ever-Decreasing Use Of Open Surgery. Eur Arco Otorhinolaryngol 2009; 266: 1333.

16. Vokes EE. Competing Ways To The Preservation Of The Larynx. j clin oncol 2013; 31: 833 .

17. Staton J, Robbins T, Newman I et al.: Factors Predictive Of Por Funcional Outcome After Chemoradiation For Advanced Laryngeal Cáncer. Otolaryngol Head Neck Surg 2002;127:43-47.

18. Timme DW, Jonnalagadda S, Patel R, et al. Treatment Selection For T3/ T4a Cancer Of The Larynx: Chemiorradiation Versus Primary Surgery. Ann Otol Rhinol Laryngol 2015; 124: 845.

19. Lefebvre Jl, Pointreau Y, Rolland F, et al. Induction Chemotherapy Followed by Chemoradiotherapy or Bioradiotherapy For The Preservation Of The Larynx: The Randomized Phase II Study Tremplin. j clin oncol 2013; 31: 853.

20. Pointreau Y, Garaud P, Chapet S, Sire C, Tuchais C, Tortochaux J, et al. Randomized Trial Of Induction Chemotherapy With Cisplatin And 5-Fluorouracil With Or Without Docetaxel For Larynx Preservation. J Natl Cancer Inst. 2009:101(7):498-506. doi: 10.1093/jnci/djp007.

21. Ljumanovic R, Langendijk Ja, Hoekstra Os, et al. mri Results Before and After radiotherapy as a Predictive Model Of Response In Laryngeal Carcinoma. eur radiol 2008; 18: 2231.
22. Induction Chemotherapy Plus Radiation Compared With Surgery Plus Radiation In Patients With Advanced Laryngeal Cancer. The Department Of Veterans Affairs Laryngeal Cancer Study Group. N Engl J Med. 1991;324(24):1685-90.

23. Holsinger FC, Nussenbaum B, Nakayama H, et al. Current Concepts And New Horizons in Laryngeal Surgery: The Preservation Of An Important Part Of Multidisciplinary Care. Head Neck 2010; 32: 656.

24. Lefebvre JL, Ang KK, Consensus Panel Preserving The Larynx. Clinical Trial Design Preservation Of The Larynx: Key Issues And Recommendations - A Summary Panel Of Consensus. head neck 2009; 31: 429.

25. Forastiere AA, Goepfert $\mathrm{H}$, Maor M, Pajak TF Weber R, Morrison W, et al. Concurrent Chemotherapy and Radiotherapy For Organ Preservation In Advanced Laryngeal Cancer. N Engl J Med. 2003;349(22):2091-8.

26. Forastiere AA, Zhang Q, Weber RS, et al. Long-Term Outcomes Of RTOG 91-11: Comparison Of Three Non-Surgical Treatment Strategies To Preserve The Larynx In Patients With Locally Advanced Laryngeal Cancer. J Clin Oncol 2013; 31: 845.

27. Pignon JP, Bourhis J, C Domenge, Designe I. Chemotherapy Add To The Locoregional Treatment For Head And Squamous Cell Carcinoma Of The Neck: Three Meta-Analyzes Of The Updated Individual Data. Mach - Nc Collaborative Group. The Meta-Analysis Of Chemotherapy In Head And Neck Cancer. Lancet 2000; 355: 949.

28. Vermorken JB, Remenar E, Van Herpen C, Gorlia T, Mesia R, Degardin M, et al. EORTC 24971/Tax 323 Study Group. Cisplatin, Fluorouracil, And Docetaxel In Unresectable Head And Neck Cancer. N Engl J Med. 2007; 357: 1695-704.

29. Pfister DG, Laurie SA, et al. American Society Of Clinical Oncology Clinical Practice Guide For The Use Of Laryngeal Conservation Strategies In The Treatment Of Laryngeal Cancer. J Clin Oncol 2006; 24: 3693.

30. Rodríguez CP, Adelstein DJ, Rybicki-la, et al. Clinical Predictors Of Laryngeal Preservation After Concurrent Multiagent Chemoradiotherapy. head neck 2008; 30: 1535 .

31. Cozzi I, Fogliata A, Bolsi A et al. Three-Dimensional Conformal vs Intensity-Modulated Radiotherapy In Head And Neck Cancer Patients: Comparative Analysis Of Dosimetric And Technical Parameters. International Journal Radiation Oncology Biology And Physics 2004; 58: 617-24.

32. Bhide S, Guerrero Urbano MT, Clark C, Hansen V, adams E, Miles E, McNair $\mathrm{H}$, Warrington A, Harrington K, Nutting C: Results of intensity modulated radiotherapy (IMRT) in laryngeal and hypopharyngeal cancer: a dose escalation study. Radiother Oncol. 2007, 82: S74-S75. 10.1016/ S0167-8140(07)80203-

33. Bonner JA, Harari PM, Giralt J, Cohen RB, Yao M, Dornfeld KJ, Buatti JM et al. Intensity-Modulated Radiation Treatment For Head-AndNeck Squamous Cell Carcinoma- The University Of lowa Experience. international journal radiation oncology biology and physics 2005; 63: 410-21.

34. Miah AB, Bhidé SA, Guerrero Urbano-MT, Clark C, Bidmead AM, Santa Rosa S, Barbachano Y, A'Hern R, Tanay M, Hickey J, Nicol R, Newbold KL, Harrington KJ, Nutting CM. Dose-scaled Intensity-Modulated Radiation Therapy Is Feasible And Can Improve Locoregional And Laryngeal Preservation Of Laryngoscope Hypopharyngeal Cancers.2012 Feb 1; 82 (2): 539-47.

35. Rancati T, Schwarz M, Allen AM, et al. Radiation dose-volume effects in the larynx and pharynx. Int J Oncol Biol Phys Radiat 2010; 76:s64.

36. DA. Low. JM Moran. JF Dempsey. L Dong y M Oldham. TG-120 "Dosimetry tools and techniques for IMRT", Med. Phys. 38, 1313-1338 (2011). 